\title{
Parents' and Teachers' Perceptions of Transition Practices in Kindergarten
}

\author{
Hariclia Harriet Petrakos and Joanne Shari Lehrer \\ Concordia University
}

\begin{abstract}
The developmental model of transition Pianta and colleagues outlined emphasizes the interconnected relationships among the child, teacher, family, peers, and community that are developed across time (Pianta \& Kraft-Sayre, 2003). This study focused on the use of transition practices as perceived by parents and teachers. Parents (8 groups) and 23 teachers of 95 children engaged in focus group discussions at the beginning and during the kindergarten year. Overall, teachers reported similar school-mandated practices, such as gradual entry, small group meetings on the first day of school, and a parent orientation meeting on the night before school starts. These transition practices were welcomed by parents and were consistent with the majority of transition practices reported in other kindergarten studies in North America (e.g., La Paro, Pianta, \& Cox 2000; Nelson, 2004; Yeom, 1998). Both parents and teachers valued communication; however, parents often found it difficult to navigate communication with the school.
\end{abstract}

Early adjustment and transition to school has been the focus of research and policy over many years. Research has described the importance of the first few years of school as predictors of later school success (e.g., Entwisle \& Alexander, 1998; Ramey \& Ramey, 2004). Children's entry into the school culture has been associated with new challenges resulting from the more heterogeneous and ethnically diverse classrooms and communities. These incongruities between home and school life pose a challenge to students, parents, and educators. For example, teachers have reported that up to $48 \%$ of children had difficulty adjusting to school (Rimm-Kaufman, Pianta, \& Cox, 2000) and the risks for children who experience difficulty transitioning have been described as academic, social, and emotional (Kagan \& Neuman, 1998). The stress associated with transition to school can place children at risk for academic failure, which is often manifested as difficulty with motivation and academic performance (Burts et al., 1992).

More recent models of family-school interaction emphasize the quality of relationships over time and the shared meaning that is created in supporting children's learning (e.g., Hamre, \& Pianta, 2001; Pianta \& Walsh, 1996). These studies described "lowrisk" circumstances as functional when home and school communication provided children with congruent messages about their schooling and "high risk" circumstances when 
children's transition to school resulted in conflicting emotions, goals, and interactions between home and school (Pianta \& Walsh, 1996).

Researchers have identified transition practices as contributing to the parent-teacher relationship and parent involvement in the student's school experience as critical outcome variables within a successful transition to elementary school (La Paro, Kraft-Sayre, \& Pianta, 2003; Schulting, Malone, \& Dodge, 2005).

The developmental model of transition describes the importance of interconnected and interdependent relationships among the child, teacher, family, peers, and community across time (Pianta \& Kraft-Sayre, 2003). This model is used as a framework for thinking about these connections and helping schools reach out to families before school starts, whenever possible, linking preschool communities with kindergarten communities to ensure that schools will be "ready" for children. Although this model can be used as a guide, the implementation of transition activities varies from school to school; in addition, the perceptions of teachers and parents impact on this process (e.g., Margetts, 2002).

The types of transition activities used by kindergarten teachers are many and varied, and have been categorized as focused on parent, student, or teacher needs (La Paro et al., 2000). The most commonly implemented type of transition practices occurs at the beginning or after the beginning of the school year and includes whole class orientation meetings, and invitations to the school and classroom (Early, Pianta, Taylor, \& Cox, 2001). Other practices include sending information packages about kindergarten curriculum. Finally, other practices such as "staggered entry" and shortening the school day, as well as individual meetings with parents and home visits, are less commonly used (e.g., Early et al., 2001). Previous research reported that teachers differed in the implementation of transition practices and that several obstacles have been reported. Teachers reported that the strain of having large class sizes, lack of funding before the children begin school, and a lack of a plan of transition by some school districts contributed to a lack of transition practices. In addition, in-service and preservice training has been influential in whether teachers used these practices or not (Early et al., 2001). Early investigations by Swick and McKnight (1989) identified teacher attitude as a significant predictor of activities promoting parental involvement and teacher education, teacher experience, teacher-child ratios, or administrative support as having less of an impact. Nevertheless, recent research has revealed that there is a wide range of differences between teachers in their attitudes towards parents, their communications skills, and their respect of teacher-parent relationships (Epstein \& Sanders, 2006; Graue, 2005; HooverDempsey, Walker, Jones, \& Reed, 2002). Therefore, teacher education programs continue to focus on parent-teacher practices during the transition to school.

The present context of the study takes place in the province of Quebec, where the government of Quebec has made school transition a priority issue in their current plan for school success (Ministère de l'Éducation, du Loisir et du Sport, 2010b). More specifically, they have recommended that links with early childhood services are necessary in order to facilitate children's transition to school. More recently, they have amended the school regulation to allow for progressive entry and have published a recent guide and call for schools, early childhood centres and social services to work together to make a school-wide transition plan (Ministère de l'Éducation, du Loisir et du Sport, 2010a).

Transition practice models have been implemented across the United States and research has explored the importance of the children's and parents' experiences of parentschool involvement. It has been suggested that parent involvement and engagement during the transition phase can ease the entry into school (Hoover-Dempsey et al., 2005). It is important to study stakeholders' experiences to understand their perceptions of transition (teacher, parent, child) and to understand how they view transition practices (Corsaro \& Molinari, 2000; Dockett \& Perry, 2005; McIntyre et al., 2007). Therefore, this qualitative 
investigation sought to understand parents' and teacher' perceptions of kindergarten transition practices and how they viewed family-school communication at the time when the children were making the transition to kindergarten.

\section{Methodology}

\section{Participants and Setting}

Parents and teachers of 95 kindergarten students who were part of a larger study on the contextual factors associated with children's transitions to school were invited to focus group discussions. Teachers were also interviewed individually at school.

Participants were affiliated with eight different English-language public schools from two different school boards, located in the suburban areas outside of Montreal, and 23 different classes, with individual schools containing between one and five kindergarten (5- to 6- year-olds) classrooms.

Teachers $(n=23)$ ranged in experience from brand new teachers who began their teaching career midway through the current school year, to experienced teachers who had been teaching kindergarten for over 20 years. Some teachers had experience teaching other grade levels or subjects in the past. The majority $(n=17)$ taught in French immersion programs, where the entire educational program was delivered in French, to Anglophone, Francophone, and bilingual students; a minority $(n=5)$ taught in English language programs to Anglophone, Francophone, and bilingual students. One teacher taught in a bilingual program where students had a French teacher and an English teacher on alternating days of the week.

All of the 95 families were invited to participate in the focus groups and to answer questionnaires on how their children were making the transition to school. For this paper, we are describing all the families (fathers and mothers) because the children's backgrounds are diverse. In addition, all of the children's teachers participated; however, only some of the families were able to take part in the focus group discussions. In total, there were eight focus groups of parents (approximately 75 parents) ranging between 3 and 10 people. The majority of parents of these children were born in Canada (62 fathers, 70 mothers) and spoke English at home (42 fathers, 44 mothers). Other languages spoken at home included French (21 fathers, 26 mothers), Arabic, Italian, Spanish, Portuguese, and others. The majority of families were two-parent families $(62.1 \%)$; a small number were single mother $(9.5 \%)$ and extended families $(6.3 \%)$, and some did not identify their family composition (15\%). Most families had two $(n=25)$ or three $(n=19)$ children, seven parents had one child, and one parent had six children.

\section{Procedure}

The teachers were individually interviewed and audio-recorded in the middle of the school year (November to February). In addition, teachers were invited to focus group discussions at the end of the school year (April to June). In total, seven focus groups were conducted with teachers. Parents were also invited to small group discussions at each of the schools between February and June of 2007. There were a total of eight parent focus groups (i.e., one per school). Although the majority of participants were mothers, in some cases fathers $(n=2)$ or both parents $(n=2)$ attended. All the focus groups were conducted by the principal investigator and audio-recorded. Childcare was offered and provided if necessary. The teachers and parents were invited to respond to questions and discussions in their preferred language, therefore the sessions were bilingual (English and French); the interviews were also conducted in the teachers' preferred language. 
Interview questions sought to understand themes related to transition practices at the beginning of and during the school year, perceptions of family and school collaboration, parenting roles, teaching roles, and their values related to education and learning (Pianta \& Kraft-Sayre, 2003). Parallel questions were designed for parents to understand their perceptions of their role in the transition to kindergarten and their perceptions of familyschool collaboration.

The audio files were analyzed using HyperRESEARCH qualitative data analysis software. Segments of text were coded and categorized inductively by four research assistants. The research assistants coded independently to illicit broader themes and then met to discuss the context of the themes and to reach consensus on the interpretation of the themes identified (Merriam, 2009). This resulted in the development of themes that both directly answered the research questions (i.e., transition practices, challenges to collaboration) and provided new perspectives about the context of the perceptions of parents with children in kindergarten (e.g., parents of children who are second-born vs. first born; teacher leaves of absence that were unpredictable). Quotes were selected that best illustrated the meaning and context of each theme; this provided "voice" to the participants in the study. The emergent themes from this dataset are discussed below.

\section{Findings and Discussion}

\section{Types of Transition Practices}

Four of the six schools took part in transition to school activities that involved meetings with the children and parents prior to the beginning of the school year, small group meetings with the children and their families on the first day of school where each child received a photograph of themselves with their teacher and parent, as well as a gradual entry during the first week. Teachers at some of the schools reported that the transition practices that were introduced at the board-level had been previously used for many years. Others explained that these practices added some new elements into their usual routine: "We've been doing progressive entry here for many years, but the format has changed...(the photo) was great, an added extra bonus."

Teachers reported similar school and board-mandated practices, such as gradual entry, small group meetings on the first day of school, and a parent-orientation meeting on the night before school starts. Teachers and parents in the majority of schools reported meetings in May or June, where all the parents whose children were registered to begin school the following September were welcomed in the gym by the school principal and other administrators or members of the school team, such as the nurse, while the teachers observed the students in their classrooms in order to determine how the classes would be divided. Registration packets were often sent early in the spring or distributed at the meeting. Orientation meetings for parents were usually held in each classroom by the classroom teacher on an evening in September after the children had entered school.

Teachers also reported practices that they chose to use individually with their classes or in cooperation with their colleagues. Teachers who believed in getting to know their students as early as possible initiated various transition practices, such as phone calls, sending postcards, or visiting children's homes in August, and sending care packages home for the parents on the first day of school. For example, one teacher described,

I sent a letter to the kids before we started school, talking about my dog, my family and the things I really liked. I asked the kids to bring in a paper bag with things that they really liked, we did a show and tell with that the first couple of weeks of school. The parents came in, I had a little package for the parents too, so they could get to know me, and I sent them a letter too, about me at home, about what kind of teacher I am, the things that I do. The parent package, it 
was a letter. There was a picture of me and my dog, oh I put a business card, I always do that, it had my name, the name of the school, the school number. It was a magnet so the parents could put it on the fridge, it had all the information. I put Kleenex cuz I know a lot of them cry when they come the first day, a tea bag, and I think I put a candy, yeah that's pretty much it, and a poem.

\section{Parent Perception of Transition Practices and Collaboration}

Parents appreciated registration packets sent home in May; they described these packets as well-organized and containing necessary information for new parents. Parents suggested that some activities, such as asking the children to visit the class prior to the first day, should be optional as they were only necessary for some children. One working parent described the different experiences she had with her sons:

I would have liked the option, cuz I was like, that's not T. (son's name), I understand the concern, but that's not him, he's outgoing, he's not going to be traumatized and my son who went through this transition in September, in a way it was kind of lost on him, he's a very outgoing child, it was fun to meet his teacher one on one, he enjoyed that, he got to see where all the toys were...but my other son who had done it 3 years before, he probably would have benefited.

Although most parents and teachers both perceived gradual entry as positive, it presented a logistical problem for working parents, if day care was not available. One of the working mothers described the challenges with gradual entry:

We need to accommodate working parents...some (parents) were saying it is just too hard...it is much more complicated for parents. The full day with half the group is very necessary...but some parents are inconvenienced by it, so it is not very good for the relationship with the parent if they are going and this is hard for me.

The gentleness for our son, we thought he was a little bit insecure, it was kind of nice for him because he got to have that picture with his teacher, and he would look at it, and he would go to bed with it, it was really nice for him...even though it was inconvenient, and it was inconvenient, but it was gentle.

Teachers at other schools noted how providing daycare services at school during the days when children attended for half days or only half the students attended could accommodate both the need for the gradual entry and the needs of working parents. Teachers did empathize with the working needs of parents, particularly if they were also parents.

Parents also reported positive feelings about their children attending small group meetings with their parent and teacher at the beginning of the school year, "with my son...I think the fact that I came in with him, it reassured him that it's safe..." and another parent added, "it was a small group so she was able to get to meet the teacher and the other kids, and get to know her room, so she had more attention, she enjoyed that."

Some parents noted that it reassured them more than their children and this was important for them to see so that they can be less stressed and perhaps their children would also benefit in the long run:

I think he was really excited about starting going to school and taking a bus, but the fact that I was there with him, reassured me. I saw he was okay, I saw right away, talking to the other kids, he was gonna be okay...

Teachers agreed that progressive entry and the small group or individual meetings with families "made a big difference for those kids who are shy, who needed extra support, not all children need it." These transition practices were welcomed by all parents and were consistent with the majority of transition practices reported in other kindergarten studies in 
North America (e.g., LaParo et al., 2000; Nelson, 2004; Yeom, 1998). It is important to consider that the careful implementation of effective transition practices may be influenced by teacher attitudes towards family-school collaboration in the long term. Even when initial transition practices were implemented, parents were not always welcomed and invited to be to be actively involved in the school (Swick \& McKnight, 1989). According to HooverDempsey and Sandler (1997), parents are involved if they are invited and if they believe they have an impact on their children's education.

\section{Teacher Perception of Transition Practices and Collaboration}

Teachers who participated in the board-wide school transition activities noted improved relationships with parents and children, as well as smoother transition in the beginning of the year. These teachers highlighted transition practices that were done early (before the start of classes). Teachers preferred meeting in small groups with their new students; for example, it was stated that

[before] our first introduction was the parent teacher interviews, and I didn't feel I could spend as much time with them or give them as much attention as I wanted to on an individual basis, whereas with the small groups it was better.

Another teacher commented on her close attachment to the child through the parent:

The children realized that the parent and their mom and dad are talking to me and we have a good relationship, smiling at each other and they felt more at ease....It is better if you meet the parents with the child because some children are very shy...also, parents that are so attached and they felt more comfortable talking to me and they told me their concerns about the child, and I had an input about the children before the start of the school year, because they told me their problems at home.

Teachers also commented on involving both children and parents, especially if the program was a change from what the child had previously experienced. One teacher discussed changes related to instructional language in school and the routines in the first few weeks of school:

I think it especially important for French Immersion, some kids come in and they are very nervous about it. I reassure them that I don't expect them to speak French right away...that relieves a lot of stress. It helps them understand the routine - the early part of the routine; where they put their lunch box, where they would be sitting, where the things were in the classroom...they weren't lost.

Another teacher reassured parents by inviting them to visit the classroom:

I have an open-door policy...(parents) can come in anytime as long as they tell me, as long as they let me know ahead of time...but I do tell the parents that if they do come in they don't just sit and observe they have to work!

Teachers felt like those who came to the interview benefitted, but were frustrated that some families did not come:

This year the parents came in and we took pictures, the children loved it, it created a bond between parents and teacher. It is too bad not all parents came in some classes, next year the letter from the principal should be more convincing.

In this case, it seemed that teachers were not forgiving of parents who did not attend the activities. It was assumed that non-involvement meant that they needed to be "convinced" and that the school principal could encourage them to attend. They did not question how they, as teachers, could be more inviting or accommodating to parents. 
Teachers also mentioned the importance of parents regulating their stress during this time for children and for their parents for the benefit of the children. This is consistent with previous studies that suggested that transition to kindergarten can be stressful for children and families and these difficulties impact on academic, social, and emotional domains (Kagan \& Neuman, 1998; Rimm-Kaufman et al., 2000). The mention of the transition to kindergarten being stressful was also described by one teacher in this way:

The kids probably they do feel it through the parents...if the parents are not anxious they have no reason to be... and yes, they can feel a little bit anxious at the beginning of the year, but if they see mom and dad are relaxed and cool that usually goes away within a few days of school.

Another teacher reminisced that she made home visits in previous years and really missed having them this year. This type of transition practice is the least commonly used by teachers, but this teacher believed that it helped parents feel more comfortable and less anxious as has been described by previous literature (i.e., Rathbun \& Germino-Hausken, 2001).

\footnotetext{
This year I did not have enough time, but what I did in the past and I loved it, was home visits; I spent half an hour talking to parents and they were so happy to see me in their kitchen. It worked very well that year; I had an amazing year that year and I had very good relationships with the kids...the kids knew when I came in...okay we've met each other and it is not a big scary thing when they came in the first day.
}

It seemed that this teacher was not given the resources (time before the children begin school) to conduct home visits. Although the benefits of home visits have been elaborated in the literature (Epstein, 2001), teachers are sometimes limited by the school policies and structures of beginning of year activities.

Finally, one teacher summarized a response that was echoed by other teachers about how transition practices could have an impact on their relationship with the child:

\footnotetext{
It surprised me...they (children) talked to me 2 weeks later...they said I have your picture on my fridge, it is not because I did not believe in that, it is just because it was new for me and it means a lot for them. We meet them in May and this little step, they know... when they came with mommy and daddy, we know each other.
}

\section{First-born vs. Later-born Children}

Both parents and teachers identified differences in parents' perceptions of transition based on whether their children were going to school for the first time. For example, some parents of first-born children discussed issues of separation and stress (e.g., new setting, new peers), whereas some parents who had older children in the school system described that they were already less nervous about their children's transition to school. One teacher explained,

For a lot of them (parents), especially when it is their first child coming they are very nervous, very nervous and it is like they are letting completely letting go, it is not like daycare where there are 8 children in the class, there are 20 children in the class and how you are going to take care of my child, and it really put them at ease I think it works and they know how open I am and it is important for them to know that I am an okay person.

Parents also discussed this as an important consideration when helping their child make the transition to school, "when it's your first kid going to kindergarten you worry about everything under the sun."

\section{Parent and Teacher Perceptions of Communication Practices}

Other communication practices discussed by teachers and parents were phone calls, informal conversation, report cards, newsletters, parent-teacher interviews, and open-house 
meetings. The more commonly reported communication practices included a school agenda and/or "pochette"(folder) that was used by teachers and parents alike to keep daily communication and share information (often initiated by the teacher), but also used by parents to ask questions. Teachers reported challenges getting parents to check the agenda or pochette. One teacher linked parent involvement to whether permission forms were returned. Another teacher related parent involvement to whether the child had a healthy lunch and was clean, whereas most teachers were more understanding about the realities of being a parent. As one teacher who was also a parent explained:

I understand, because I can't go to my children's trips in their school and I have to take full days off, and I do... but I can't go to half day trips....I have 18 little children waiting for and I cannot not show up.

Teachers drew on personal experiences as a parent and a student in explaining how and why they communicated, while parents praised experienced teachers with many years of teaching or with many children of their own for being able to effectively communicate and build relationships with them: "our teacher has four children, so I think she knows what not to do and to do very well...her own mother experience, she kind of knows" and

the communication really depends on the teacher...they've been here a while, they're not new teachers, they're not fresh out of school, they know how to handle the children...I've never had a problem getting in touch with her...I come in to see her when I have no appointment, she stops, she has big pile of stuff, she always stops and talks to me.

Despite the number of communication practices parents and teachers reported, most of the parents across all schools reported not getting enough information on what is going on in school and on their children's individual progress other than parent-teacher conferences. Follow up notes or contact was suggested, and this was deemed important to facilitate an easier transition and more informed parent involvement: "there's no feedback, so we're hoping he's doing well because we're not getting any negative feedback...that's why we've made the effort to volunteer...so we can see how he's doing, who he's playing with," "I asked for a meeting with the new teacher, we never received an answer," and

we used to get a little sheet, it said what they would learn every week...this week the theme is

blah blah blah, this is what their homework is...now, except for pictures that come home, is he

doing it at daycare? is he doing it at kindergarten? you have no clue

Overall, it seemed that parents were not informed of their children's day-to-day activities and therefore did not feel invited as collaborators in the educational process. There was no mention of parental knowledge as described by the literature on parent involvement that depicts a parent's knowledge about the child as a resource to the teacher and to the classroom in general (e.g., Hoover-Dempsey et al., 2005; Kelly, 1995).

Parents from all schools noted the importance of communication between home and school as a factor that influenced their involvement and ability to ease their children's transition to school. When communication was difficult, one parent reported that "...if you don't have the time to actually be there physically you don't get the information." Knowing what occurs at school was important to parents in facilitating the transition, as well as reinforcing learning at home.

While some teachers focused on the child's transition and teacher-child relationship, others also highlighted the importance and value of the parent-teacher relationship as an influence on the teacher-child relationship. One parent described the stress of the transition and the parent-teacher relationship: "I find the teacher makes a big difference too, if you're comfortable with your teacher, you'll feel a lot more at ease about how your child is progressing at school." 


\section{The Role of the Parent and the Goal for Kindergarten}

Kindergarten teachers mentioned that one of the goals of kindergarten was the importance of establishing a routine for homework. In this regard, teachers spent time during orientation meetings on this topic and described that parent involvement with homework would lead to a successful school transition. Teachers perceived homework as a way to "train" parents and children and this was not always welcomed by parents who felt they had many activities and a different role when their child came home:

I don't call it homework. For them to have an organized, a quiet time, spend 5-10 minutes once a week, to get used to it, make the child feel special and prepared for homework in grade one, play games with numbers, vocabulary...

Another teacher reflected on her own experience as a parent and showed understanding for parents who may find it challenging to juggle parenting and working:

I want parents to know that we are not here to raise their children. Like tying their shoes, how
to eat properly...I will not go to a parent and tell them that. When they first come in the ones
that cannot tie the shoes or they don't know their letters, or don't know how to count, I don't
care, that's my job, I will teach them. There is a lot of pressure put on parents... some children
are not ready.

Although some parents perceived their role as necessary in reaching this goal, other parents had a long-term vision of developing autonomy by giving their child the responsibility of emptying their school bag and showing parents what they need to sign. These parents accepted that sometimes a permission form may not be signed, but that having to answer to the teacher will help their child become more responsible. These types of differences in perceptions of parents' roles and goals for children could be helpful in informing school policies about these school practices and using parenting input and feedback as a basis for developing these policies.

\section{Parent Engagement in Volunteering}

During the transition to school activities, parents were invited to volunteer during school trips and in the classroom. This practice was believed to help parents feel more included in the school and children to feel that their families were welcomed in the school. Parents reported that volunteering in the classroom was not always possible when they were working parents or stayed at home with younger siblings. These transition activities were not useful when there were barriers such as policies that did not allow younger siblings to come along or work policies that did not allow parents to take time off. Parents who could not volunteer for school trips or bake sales reported feeling guilty, although most teachers were understanding of parents who could not volunteer in the school setting. This was in contrast to the literature on parent involvement that described the importance of accommodating parents so that they can be more involved in the classroom (e.g., Epstein, 2001); when parents had younger siblings at home, the teachers did not allow or invite the parents to bring the younger children along to fieldtrips.

Other teachers reported that they depended on parent volunteers in order to teach the curriculum, "a teacher who doesn't have parent volunteers can't do the same activities in the computer lab as other teachers." The schools varied in their expectations of parents as volunteers, with some teachers having an open-door policy (one teacher) to others expecting very little in-school involvement. Another parent spoke about the unrealistic school expectations for parents and families: 
Last year I had pneumonia 2 or 3 times, and I had a lot of family problems and I worked nights and I couldn't help my son the way I used to... and the teacher said, "you know he has been absent many times do you want to tell me why"...they made me feel really bad. I had a lot of stuff and they don't need to know about...I get him there!

Other involvement in school was identified by teachers as identifying and recruiting new parents who would be willing to be involved in the governing board or the home and school organization. Although these activities do not seem at first to be related to transition planning, if one takes the approach that transition to school encompasses the whole year and each year after that, parent involvement in such activities facilitates the transition process over the year and the children and teachers begin to see parents as part of the educational process.

\section{Conclusions}

The developmental model of school transition includes both the process of transition and the experiences of those involved, namely, children, parents, and teachers. The relationships between the child and the teacher and the relationships between the parents and the teacher are being examined in current research and linked to successful transition and school success (e.g., Dockett \& Perry, 2003, 2005; Ledger, Smith, \& Rich, 2000).

In this study, the interviews and focus group discussions provided an in-depth look at the priorities that parents and teachers hold regarding the transition practices to kindergarten. By examining the data from these individual interviews and focus group discussions, a number of themes emerged regarding transition practices, parent-teacher communication, and relationships. Teachers highlighted the positive impact of having administrative support to engage in transition practices and work on effective communication with parents and children. Both parents and teachers believed that positive communication practices reduced the stress associated with the transition to school. Finally, both believed that the communication practices in kindergarten may set the stage for future transition and school expectations. In this first year of school, teachers encouraged parent engagement and volunteering in the classroom and in the home-school organizations (e.g., governing board and home-school associations). Teachers continued to believe that the more traditional forms of volunteerism (class) and homework support were important for all parents, whereas parents described the quality of interactions with teachers and the importance of not feeling judged and having realistic and inclusive practices for working parents or families who could not be physically present in school.

\section{References}

Burts, D. C., Hart, C. H., Charlesworth, R., Fleege, P. O., Mosley, J., \& Thomasson, R. H. (1992). Observed activities and stress behaviors of children in developmentally appropriate and inappropriate kindergarten classrooms. Early Childhood Research Quarterly, 7, 297-318. doi:10.1016/0885-2006(92)90010-V

Corsaro, W. A., \& Molinari, L. (2000). Priming events and Italian children's transition from preschool to elementary school: Representations and action. Social Psychology Quarterly, 63(1), 16-33. doi:10 .2307/2695878

Dockett, S., \& Perry, B. (2003). The transition to school: What's important? Educational Leadership, 6(7), 30-33. Retrieved from http://www.ascd.org/publications/educational-leadership.aspx

Dockett, S., \& Perry, B. (2005). Researching with children: Insights from the Starting School Research Project. Early Child Development and Care, 17(6), 507-521. doi:10.1080/03004430500131312

Early, D. M., Pianta, R. C., Taylor, L. C., \& Cox, M. J. (2001). Transition practices: Findings from a national survey of kindergarten teachers. Early Childhood Education Journal, 28(3), 199-206. doi: 10.1023/A:1026503520593 
Entwisle, D. R., \& Alexander, K. L. (1998). Facilitating the transition to first grade: The nature of transition and research on factors affecting it. Elementary School Journal, 98(4), 351-364. doi: $10.1086 / 461901$

Epstein, J. L. (2001). School, family and community partnerships. Boulder, CO: Westview.

Epstein, J. L., \& Sanders, M. G. (2006). Prospects for change: Preparing educators for school, family, and community partnerships. Peabody Journal of Education, 81(2), 81-120. doi:10.1207 /S15327930pje8102_5

Graue, E. (2005). Theorizing and describing preservice teachers' images of family and schooling. Teachers College Record, 107(1), 157-185. doi:10.1111/j.1467-9620.2005.00461.x

Hamre, B. K., \& Pianta, R. C. (2001). Early teacher-child relationships and the trajectory of children's school outcomes through eighth grade. Child Development, 72(12), 147-159. doi:10.1111/1467 $-8624.00301$

Hoover-Dempsey, K. V., \& Sandler, H. (1997). Why do parents become involved in their children's education? Review of Educational Research, 67(1), 3-42. doi:10.3102/00346543067001003

Hoover-Dempsey, K. V., Walker, J. M. T., Jones, K. P., \& Reed, R. P. (2002). Teachers Involving Parents (TIP): An in-service teacher education program for enhancing parental involvement. Teaching and Teacher Education, 18(7), 1-25. doi:10.1016/S0742-051X(02)00047-1

Hoover-Dempsey, K. V., Walker, J. M. T., Sandler, H. M., Whetsel, D., Green, C. L., Wilkins, A. S., \& Closson, K. (2005). Why do parents become involved? Research findings and implications. The Elementary School Journal, 106(2), 105-130. doi:10.1086/499194

Kagan, S. L., \& Neuman, M. J. (1998). Lessons from three decades of transition research. The Elementary School Journal, 98(4), 365-380. doi:10.1086/461902

Kelly, C. (1995). Parents as partners. Early Childhood Review, 1, 1-27. doi:10.1016/0021-9924(95)00004 $-\mathrm{W}$

La Paro, K., Kraft-Sayre, M., \& Pianta, R. (2003). Preschool to kindergarten transition activities: Involvement and satisfaction of families and teachers. Journal of Research in Childhood Education, 17(2), 147-158. doi:10.1080/02568540309595006

La Paro, K., Pianta, R., \& Cox, M. (2000). Kindergarten teachers' reported use of kindergarten to first grade transition practices. The Elementary School Journal, 101(1) 63-78. doi:10.1086/499659

Ledger, E., Smith, A. B., \& Rich, P. (2000). Friendships over the transition from early childhood centre to school. International Journal of Early Years Education, 8(1), 57-69. Retrieved from http://www .tandf.co.uk/journals/titles/09669760.asp

Margetts, K. (2002). 'Transition to school-complexity and diversity.' European Early Childhood Education Research Journal, 10(2), 103-114. doi:10.1080/13502930285208981

McIntyre, L. L., Eckert, T. L., Fiese, B. H., DiGennaro, F. D., \& Wildenger, L. K. (2007). Transition to kindergarten: Family experiences and involvement. Early Childhood Education Journal, 35(1), 83-88. doi:10.1007/s10643-007-0175-6

Merriam, S. (2009). Qualitative research and case study applications in education (2nd ed.). San Francisco, CA: Jossey Bass.

Ministère de l'Éducation, du Loisir et du Sport. (2010a). Guide for supporting a successful school transition. Quebec, QC: Gouvernement de Quebec.

Ministère de l'Éducation, du Loisir et du Sport. (2010b). I care about school. Quebec, QC: Gouvernement de Quebec.

Nelson, R. F. (2004). The transition to kindergarten. Early Childhood Education Journal, 32(3), 187-190. doi:10.1023/B:ECEJ.0000048971.21662.01

Pianta, R., \& Kraft-Sayre, M. (2003). Successful kindergarten transition: Your guide to connecting children, families, \& schools. Baltimore, MD: Paul H. Brookes.

Pianta, R., \& Walsh, D. B. (1996). High-risk children in schools: Constructing sustaining relationships. New York, NY: Routledge.

Ramey, C. T., \& Ramey, S. L. (2004). Early learning and school readiness: Can intervention make a difference? Merrill Palmer Quarterly, 50(4), 471-491. doi:10.1353/mpq.2004.0034

Rathbun, A. H., \& Germino-Hausken, E. (2001, April). How are transition-to-kindergarten activities associated with parent involvement during kindergarten? Paper presented at the Annual Meeting of the American Educational Research Association, Seattle, WA.

Rimm-Kaufman, S. E., Pianta, R. C., \& Cox, M. J. (2000). Teachers' judgments of problems in the transition to kindergarten. Early Childhood Research Quarterly, 15(2), 147-166. doi:10.1016/S0885 $-2006(00) 00049-1$ 
Schulting, A., Malone, P., \& Dodge, K. (2005). The effect of school-based kindergarten transition policies and practices on child academic outcomes. Developmental Psychology, 41(6), 860-871. doi:10 $.1037 / 0012-1649.41 .6 .860$

Swick, K. J., \& McKnight, S. (1989). Characteristics of kindergarten teachers who promote parent involvement. Early Childhood Research Quarterly, 4, 19-29. doi:10.1016/S0885-2006(89)900380

Yeom, J. S. (1998). Children's transition experiences from kindergarten to grade one. Canadian Children, 23(1), 25-33. Retrieved from http://www.cayc.ca/Journal.html

\section{Authors' Note}

Correspondence concerning this article should be addressed to Hariclia Petrakos, Department of Education, Concordia University, 1455 de Maisonneuve west, LB-579, QC H3G 1M8. Email: HPETRAKOS@education.concordia.ca

This project was part of a larger 2-year longitudinal research project on children's transition to school, entitled, A two-year study of the psycho-social and contextual factors associated with children's early transition to school supported by the SSHRC. 